\title{
Article \\ A Comparison of Patients Undergoing On- vs. Off-Pump Coronary Artery Bypass Surgery Managed with a Fast-Track Protocol ${ }^{+}$
}

\author{
Henrike Grützner ${ }^{1, \ddagger}$, Anna Flo Forner ${ }^{2, \ddagger}$, Massimiliano Meineri ${ }^{2}$, Aniruddha Janai ${ }^{2}$, Jörg Ender $^{2}$ \\ and Waseem Zakaria Aziz Zakhary ${ }^{2, *}$
}

1 Section for Pediatrics and Youth Medicine, Public Health Department, Leipzig City Government, Friedrich-Ebert-Straße 19 a, 04109 Leipzig, Germany; henrike.gruetzner@leipzig.de

2 Department of Anesthesiology and Intensive Care Medicine, Heart Center Leipzig, Strümpellstraße 39, 04289 Leipzig, Germany; anna.floforner@helios-gesundheit.de (A.F.F.);

Massimiliano.Meineri@helios-gesundheit.de (M.M.); aniruddha.janai@helios-gesundheit.de (A.J.); Joerg.Ender@helios-gesundheit.de (J.E.)

* Correspondence: WaseemZakariaAziz.Zakhary@helios-gesundheit.de

+ Presented in part at the European Association of Cardiothoracic Anesthesiology (EACTA) 2020, Grenoble, France (online congress).

$\ddagger \quad$ H.G. and A.F.F. contributed equally to this work.

check for updates

Citation: Grützner, H.; Flo Forner, A.; Meineri, M.; Janai, A.; Ender, J.; Zakhary, W.Z.A. A Comparison of Patients Undergoing On- vs. Off-Pump Coronary Artery Bypass Surgery Managed with a Fast-Track Protocol. J. Clin. Med. 2021, 10, 4470. https://doi.org/10.3390/jcm10194470

Academic Editor: Heinrich

Volker Groesdonk

Received: 24 August 2021

Accepted: 22 September 2021

Published: 28 September 2021

Publisher's Note: MDPI stays neutral with regard to jurisdictional claims in published maps and institutional affiliations.

Copyright: (c) 2021 by the authors. Licensee MDPI, Basel, Switzerland. This article is an open access article distributed under the terms and conditions of the Creative Commons Attribution (CC BY) license (https:// creativecommons.org/licenses/by/ $4.0 /)$.
Abstract: The purpose of this study was to compare patients who underwent on- vs. off-pump coronary artery bypass surgery managed with a fast-track protocol. Between September 2012 and December 2018, $n=3505$ coronary artery bypass surgeries were managed with a fast-track protocol in our specialized post-anesthesia care unit. Propensity score matching was applied and resulted in two equal groups of $n=926$. There was no significant difference in ventilation time (on-pump 75 (55-120) min vs. off-pump $80(55-120) \mathrm{min}, p=0.973)$. We found no statistically significant difference in primary fast-track failure in on-pump $(8.2 \%$ (76)) vs. off-pump $(6 \%$ (56)) groups $(p=0.702)$. The secondary fast-track failure rate was comparable (on-pump $12.9 \%$ (110) vs. offpump $12.3 \%(107), p=0.702)$. There were no significant differences between groups in regard to the post-anesthesia care unit, the intermediate care unit, and the hospital length of stay. Postoperative outcome and complications were also comparable, except for a statistically significant difference in PACU postoperative blood loss in on-pump ( $234 \mathrm{~mL})$ vs. off-pump $(323 \mathrm{~mL}, p<0.0001)$ and red blood cell transfusion $(11 \%)$ and $(5 \%, p<0.001)$, respectively. Our results suggest that on- and off-pump coronary artery bypass surgery in fast-track settings are comparable in terms of ventilation time, fast-track failure rate, and postoperative complications rate.

Keywords: fast-track cardiac anesthesia; recovery area; on-pump coronary artery bypass surgery; off-pump coronary artery bypass surgery; ventilation time

\section{Introduction}

Coronary artery bypass grafting (CABG) can be performed with the use of cardiopulmonary bypass (on-pump-CABG) or without (off-pump CABG). Studies comparing onto off-pump CABG have consistently reported longer postoperative mechanical ventilation time and longer ICU- and hospital length of stay in the on-pump group [1-3], possibly explained by aortic manipulation and cardiopulmonary bypass (CPB)-triggered pro-inflammatory response which increased the risk of myocardial damage, adverse neurologic events and renal injury [4].

Fast-track cardiac anesthesia aims to reduce ventilation time, intensive care unit (ICU)- and consequently hospital-length of stay to optimize resource utilization [5]. Fast tracking can be performed in the ICU or in a specialized post-anesthesia care unit (PACU), thus completely avoiding ICU admission [6]. Fast-track management through a PACU 
proved to be a safe option for cardiac surgical patients at low-to-moderate risk and leads to reduced ventilation time as well as reduced ICU length of stay $[7,8]$. Tight intraoperative temperature management, optimal surgical hemostasis and hemodynamic stability are the prerequisites for successful fast-tracking [9]. Furthermore, a fast-track protocol has been shown to be safe $[10,11]$, improve outcome [12], and reduce costs [5,13], after both on- or off-pump CABG. However, only one study to date has compared these two surgical approaches for myocardial revascularization using the same protocol [14].

The aim of this study was to compare the postoperative course of patients undergoing on- vs. off-pump CABG managed through a specialized PACU and the same fast-track protocol [15]. Primary endpoints were mechanical ventilation time (from arrival in PACU to tracheal extubation) and primary fast-track failure (unplanned transfer from PACU to ICU or the operating room). Secondary endpoints included PACU, intermediate care unit (IMC) and in hospital length of stay, re-intubation rate, and secondary fast-track failure (transfer from IMC or ward to the ICU or IMC, respectively) and postoperative outcomes measurements (e.g., blood transfusion, major adverse cardiovascular events, mortality).

\section{Materials and Methods}

This retrospective study was approved by the local ethics committee (approval number 178/19-ek from 30 April 2019) and performed in a single heart center. Individual patient consent was waived, given the retrospective observational nature of the study. Inclusion criteria were on- or off-pump CABG and fast-track management through a specialized PACU between September 2012 and December 2018. Patients who were intraoperatively converted from off-pump to on-pump surgery were excluded from the study. Patients operated on between February and July 2017 were excluded because of a temporary change in a fast-track protocol due to a shortage of remifentanil.

\subsection{Anesthesia Management}

Dipotassium clorazepate 10-20 mg was orally administered as premedication the evening before the operation when deemed necessary. The induction of general anesthesia was achieved using propofol $1-2 \mathrm{mg} / \mathrm{kg}$, fentanyl $200 \mu \mathrm{g}$ and a single dose of rocuronium $(0.5-0.6 \mathrm{mg} / \mathrm{kg})$ or atracurium $(0.3-0.6 \mathrm{mg} / \mathrm{kg}) \mathrm{I} . \mathrm{V}$. for neuromuscular blockade. After endotracheal intubation, a three-lumen central venous catheter and $8.5 \mathrm{~F}$ introducer sheath were inserted in the right internal jugular vein under ultrasound guidance; body temperature was monitored in the bladder though a urinary catheter and using a nasopharyngeal temperature probe. Transesophageal echocardiography was performed only when indicated (i.e., reduced ejection fraction or known pulmonary hypertension). Finally, pulse contour analysis (Vigileo ${ }^{\circledR}$, Edwards Lifesciences, California, CA, USA) was used for all off-pump cases. Anesthesia was maintained by a continuous infusion of remifentanil $0.2-0.3 \mu \mathrm{g} / \mathrm{kg} / \mathrm{min}$ I.V. and sevoflurane at a minimum alveolar concentration of $0.8-1.1 \%$. During CPB, patients received a continuous infusion of propofol $3 \mathrm{mg} / \mathrm{kg} / \mathrm{h} \mathrm{I.V}$. For all off-pump cases, an external forced-air warming system (3M ${ }^{\mathrm{TM}}$ Bair Hugger ${ }^{\mathrm{TM}}$ Full Access Underbody Blanket 63500, Minnesota, MN, USA) was used from before induction until it was transferred to PACU and set to keep the core temperature $\geq 36{ }^{\circ} \mathrm{C}$. The same system was used in on-pump CABG cases and turned on at the time of re-warming during $\mathrm{CPB}$. It was finally utilized in the PACU if the core temperature was $<36{ }^{\circ} \mathrm{C}$ on admission. All infusions and blood products were warmed though the LEVEL 1 HOTLINE ${ }^{\circledR}$ Blood and Fluid Warmer (Smiths Medical, Minnesota, MN, USA).

Red blood cells' transfusion was triggered by a hematocrit less than $20 \%$ during $\mathrm{CPB}$, or less than $25 \%$ after weaning from $\mathrm{CPB}$ and during off-pump surgery.

\subsection{Surgical Management}

The decision to select on- or off-pump procedure as well as the type and number of grafts was based on the patient's condition (e.g., porcelain aorta or mobile plaques) and the surgeon's preference. 
Intraoperatively, all patients received unfractionated heparin as anticoagulant and its effect was monitored using activated clotting time (ACT). For on-pump CABG, patients received 300-500 IU $/ \mathrm{kg}$ heparin to reach an ACT above $480 \mathrm{~s}$, while off-pump CABG patients received 150-250 IU $/ \mathrm{kg}$ heparin to reach an ACT above $300 \mathrm{~s}$.

CPB management protocol were the same for all on-pump patients. When needed, antegrade blood or crystalloid-based Bretschneider cardioplegia solution (Custodiol ${ }^{\circledR}$ Dr. Franz Köhler Chemie GmbH, Bensheim, Germany) was used according to the surgeon's preference. Normothermia $\left(>34^{\circ} \mathrm{C}\right)$ or mild hypothermia $\left(32-34{ }^{\circ} \mathrm{C}\right)$ was maintained in most of cases during $\mathrm{CPB}$.

\subsection{Management in PACU}

At the end of the surgery, when the fast-track criteria were met and agreed upon by both the surgeon and the anesthesiologist, the patient was transferred to PACU. Fast-track criteria were defined as hemodynamic stability, a core temperature of $\geq 36{ }^{\circ} \mathrm{C}$, minimal inotropic support (continuous infusion of $<0.1 \mathrm{mg} / \mathrm{kg} / \mathrm{min}$ of norepinephrine and/or $<0.05 \mathrm{mg} / \mathrm{kg} / \mathrm{min}$ of epinephrine or $<4 \mu \mathrm{g} / \mathrm{kg} / \mathrm{min}$ of dobutamine) and satisfactory hemostasis. The PACU was open from Monday to Friday 10:00 a.m.-10:30 p.m. with one anesthesiologist every four patients and one nurse every three patients.

Upon arrival at the PACU, patients received metamizole $1 \mathrm{~g} \mathrm{I.V.} \mathrm{and} \mathrm{piritramide}$ $0.1 \mathrm{mg} / \mathrm{kg}$ I.V. for postoperative analgesia. Extra boluses of piritramide $0.02-0.03 \mathrm{mg} / \mathrm{kg}$ I.V. were given as needed to achieve a pain numeric rating scale inferior to 4 .

Patients were extubated when they were fully conscious and hemodynamically stable. Afterwards, they were monitored for a minimum of two hours and then transferred to the IMC when fulfilling the criteria determined by the fast-track protocol [15].

Primary fast-track failure was defined as an unplanned transfer from the recovery unit to the ICU or back to the operating room. Transfers from the IMC or ward back to the ICU or IMC, respectively, were considered as secondary fast-track failure (Figure 1).

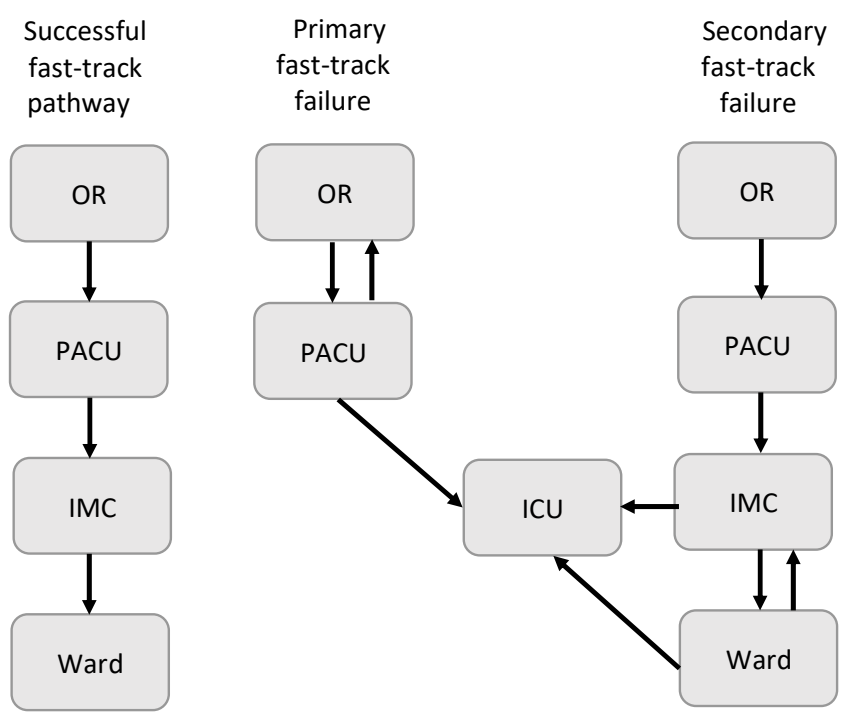

Figure 1. Types of fast-track failure. $\mathrm{OR}=$ operating room; PACU = postanesthetic care unit, $\mathrm{IMC}=$ intermediate care unit, ICU = intensive care unit.

\subsection{Data Collection and Analysis}

The primary anesthesiologist scanned the anesthesia chart and the PACU observation chart using the machine-readable patient's chart Medlinq ${ }^{\circledR}$ software (Medlinq Softwaresysteme $\mathrm{GmbH}$, Hamburg, Germany). Manual corrections were allowed before final charts' saving in case of unreadable handwriting or inconsistencies. The author H.G. collected all data retrospectively from the clinical information system iMedOne ${ }^{\circledR}$ (Deutsche Telekom Healthcare and Security Solutions GmbH, Bonn Germany), clinical information system 
Clemens $^{\circledR}$ (Teratec GmbH, Münster, Germany), and the patient's chart Medlinq ${ }^{\circledR}$. SPSS (SPSS $^{\circledR}$ Statistics 25.0; Chicago, IL, USA) and StatsDirect (StatsDirect ${ }^{\circledR}$ version 3.0, StatsDirect Ltd., Cheshire, UK) were used for data description and analysis.

To guarantee two comparable groups and to minimize selection bias on the primary endpoint, we used propensity score matching. To build the logistic regression model, several variables, known to affect postoperative ventilation time and fast-track failure, were included. Specifically: age, gender, body mass index, American Society of Anesthesiologists physical status classification, logistic EuroSCORE, preoperative left ventricular ejection fraction, New York Heart Association Functional Classification, comorbidities, and duration of surgery. We used one-to-one matching and paired each subject to the closest propensity score subject from the other group. Based on the pre-matching range of baseline variable differences, the maximum caliper width for pair-matching was defined as 0.125 of the pooled logit score standard deviation.

Continuous variables were assessed for the normal distribution using the ShapiroWilk's test. The data are expressed as the mean (standard deviation) and compared using Student's t-test when normally distributed; otherwise, the results are expressed as median (interquartile range). Mann-Whitney-U-test was used for comparisons. Categorical data were expressed as numbers (proportion) and compared using the $X^{2}$-test or Fisher's exact test where appropriate. A $p$-value $<0.05$ was considered statistically significant.

\section{Results}

Between 2012 and 2018, 5886 coronary bypass operations were performed at our institution, 3505 of which were managed with a fast-track protocol. Propensity score matching yielded two equal groups $n=926$, thus excluding overall 1653 patients (Figure 2).

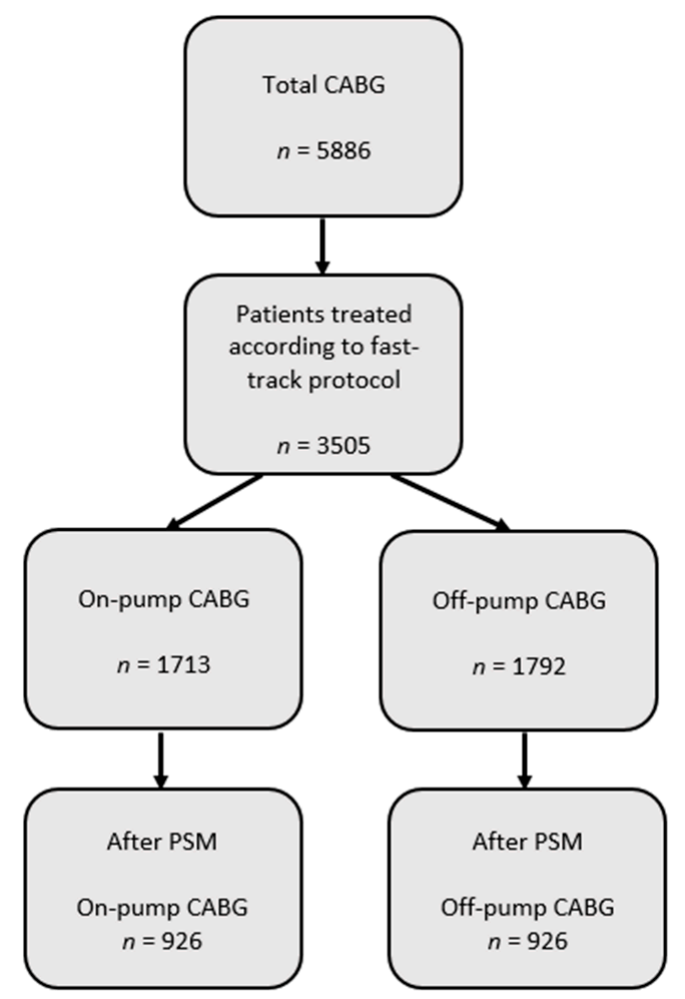

Figure 2. Patients flowchart. $\mathrm{CABG}=$ coronary artery bypass grafting; PSM = propensity score matching.

The patient's baseline characteristics and operative data were comparable and shown in Table 1. 
Table 1. Baseline characteristics and operative data for patients included in the study. Values are the mean (SD) or number (\%).

\begin{tabular}{|c|c|c|c|}
\hline & $\begin{array}{c}\text { On-Pump Group } \\
n=926\end{array}$ & $\begin{array}{c}\text { Off-Pump Group } \\
n=926\end{array}$ & $p$-Value \\
\hline Age: years & $68.7(9.6)$ & $68.4(8.7)$ & 0.494 \\
\hline Gender: female & $171(18.4 \%)$ & $169(18.2 \%)$ & 0.952 \\
\hline BMI & $28.8(4.6)$ & $28.5(4.4)$ & 0.299 \\
\hline Smoking & $420(45.3 \%)$ & $399(43 \%)$ & 0.349 \\
\hline Logistic EuroSCORE & $4.4(4.4)$ & $4.4(4.9)$ & 0.995 \\
\hline LV ejection fraction; \% & $54.4(10.3)$ & $54.5(10.3)$ & 0.832 \\
\hline Myocardial infarction & $322(34.7 \%)$ & $313(33.8 \%)$ & 0.695 \\
\hline Cerebrovascular accident & $56(6 \%)$ & $59(6.3 \%)$ & 0.847 \\
\hline COPD & $40(4.3 \%)$ & $34(3.6 \%)$ & 0.553 \\
\hline Diabetes mellitus & $386(41.6 \%)$ & $373(40.2 \%)$ & 0.570 \\
\hline Pulmonary hypertension & $149(16 \%)$ & $182(19.6 \%)$ & 0.052 \\
\hline Arterial hypertension & $892(96.3 \%)$ & $887(95.7 \%)$ & 0.632 \\
\hline $\begin{array}{l}\text { Peripheral vascular disease } \\
\text { NYHA }\end{array}$ & $182(19.6 \%)$ & $183(19.7 \%)$ & $>0.999$ \\
\hline NHYA I & $162(17.4 \%)$ & $154(16.6 \%)$ & 0.665 \\
\hline NYHA II & $411(44.3 \%)$ & $428(46.2 \%)$ & 0.455 \\
\hline NNYHA III & $331(35.7 \%)$ & $325(35.1 \%)$ & 0.808 \\
\hline NHYA IV & $22(2.3 \%)$ & $19(2.0 \%)$ & 0.752 \\
\hline Preoperative creatinine; $\mu \mathrm{mol} / \mathrm{L}$ & $93.7(50)$ & $91(38)$ & 0.221 \\
\hline Duration of surgery; min & $208.2(61)$ & $209.2(60)$ & 0.276 \\
\hline
\end{tabular}

$\mathrm{BMI}=$ body mass index; ASA =American Society of Anesthesiologists physical status classification system; $\mathrm{LV}=$ left ventricle; $\mathrm{COPD}=$ chronic obstructive pulmonary disease; NYHA = New York Heart Association Functional Classification.

The duration of mechanical ventilation was not significantly different between the groups (Figure 3).

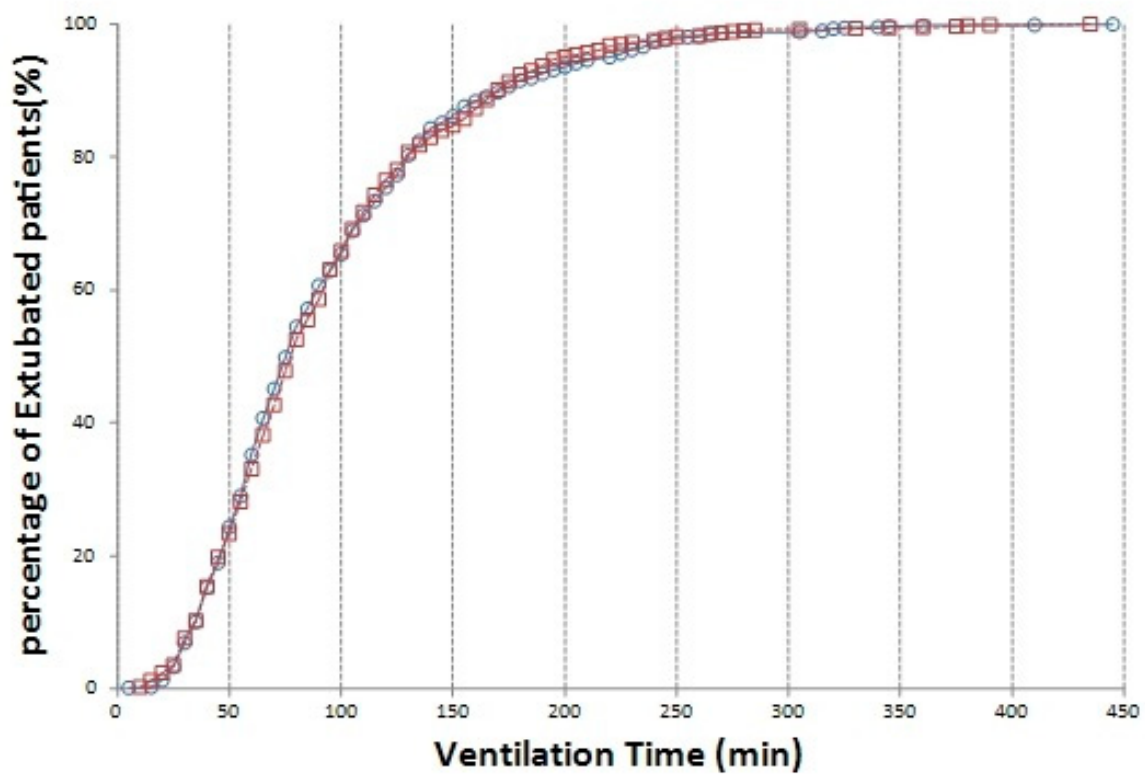

Figure 3. Comparison of ventilation time between on- (blue circles) and off-pump (red squares) group.

There were no significant differences between groups in terms of PACU, IMC or hospital length of stay (Table 2). Furthermore, there was no significant difference in the primary and secondary fast-track failure in the on- compared to off-pump CABG (Table 3). Postoperative complications were also comparable, except for statistically significant differences in in-PACU postoperative bleeding, which was higher for the off-pump group and a higher perioperative and in-PACU red blood cell (RBC) transfusion rate for the on-pump group (Table 3). 
Table 2. Postoperative outcome parameters for patients included in the study. Values are median (IQR (range)).

\begin{tabular}{cccc}
\hline & On-Pump Group & Off-Pump Group & $\boldsymbol{p}$-Value \\
& $\boldsymbol{n = 9 2 6}$ & $\mathbf{n = 9 2 6}$ & 0.973 \\
Ventilation time, min & $75(55-120(65))$ & $80(55-120(65))$ & 0.702 \\
PACU LOS, min & $260(255-315(105))$ & $255(210-310(100))$ & 0.237 \\
Intermediate care unit LOS, h & $28.5(17-65(47))$ & $32.8(18-67(49))$ & 0.069 \\
Hospital LOS, d & $8(7-11(4))$ & $8(7-11(4))$ & \\
\hline
\end{tabular}

LOS-length of stay; PACU—-postanesthetic care unit.

Table 3. Postoperative outcome and complications for patients included in the study. Values are the mean (SD) or number (proportion).

\begin{tabular}{|c|c|c|c|}
\hline & $\begin{array}{c}\text { On-Pump Group } \\
n=926\end{array}$ & $\begin{array}{l}\text { Off-Pump Group } \\
\quad n=926\end{array}$ & $p$-Value \\
\hline Primary FTF & $76(8.2 \%)$ & $56(6 \%)$ & 0.071 \\
\hline FTF and re-do due to bleeding & $9(1 \%)$ & $4(0.4 \%)$ & 0.178 \\
\hline Secondary FTF & $110(12.9 \%)$ & $107(12.3 \%)$ & 0.702 \\
\hline Re-intubation & $9(1.0 \%)$ & $7(0.7 \%)$ & 0.610 \\
\hline Lactate, $\mu \mathrm{mol} / \mathrm{L}$ & $1.4(1.0)$ & $1.4(0.9)$ & 0.261 \\
\hline In-PACU postoperative bleeding, $\mathrm{ml}$ & $234(243)$ & $323(247)$ & $<0.001$ \\
\hline $\begin{array}{l}\text { Number of patients having received } \\
\text { RBCs transfusion (perioperative) }\end{array}$ & $333(35 \%)$ & $208(22 \%)$ & $<0.001$ \\
\hline $\begin{array}{c}\text { Total of transfused RBC units } \\
\text { (perioperative) }\end{array}$ & 930 & 564 & \\
\hline $\begin{array}{c}\text { Perioperative RBCs transfusion, } \\
\text { units/patient }\end{array}$ & $1(1.7)$ & $0.6(1.4)$ & $<0.001$ \\
\hline $\begin{array}{c}\text { Number of patients received RBCs } \\
\text { transfusion (PACU) }\end{array}$ & $100(11 \%)$ & $50(5 \%)$ & $<0.001$ \\
\hline Total of transfused RBC units (PACU) & 147 & 82 & \\
\hline In-PACU RBCs transfusion, units/patient & $0.15(0.8)$ & $0.1(0.4)$ & 0.024 \\
\hline Highest serum creatinine, $\mu \mathrm{mol} / \mathrm{L}$ & 89.7 (117) & $89.1(110)$ & 0.897 \\
\hline Postoperative renal dialysis & $27(2.9 \%)$ & $16(1.7 \%)$ & 0.092 \\
\hline Cardiac arrhythmias & $209(22.5 \%)$ & $193(20.8 \%)$ & 0.367 \\
\hline Cerebrovascular accident & $12(1.3 \%)$ & $10(1 \%)$ & 0.675 \\
\hline Myocardial infarction & $1(0.1 \%)$ & $5(0.53 \%)$ & 0.124 \\
\hline Mortality & $18(1.9 \%)$ & $22(2.3 \%)$ & 0.528 \\
\hline
\end{tabular}

FTF $=$ fast-track failure; RBCs $=$ red blood cells.

\section{Discussion}

In our study, we could find no significant difference between on- vs. off-pump CABG patients managed with a fast-track protocol in a specialized PACU, in terms of time to tracheal extubation, primary and secondary fast-track failure and PACU, IMC, and hospital length of stay. Postoperative outcome and complications were comparable, except for a statistically significant higher blood loss in the off-pump group and higher RBC transfusion rate in the on-pump group.

Most previous studies and meta-analyses compared on- vs. off-pump CABG using conventional perioperative anesthetic management and demonstrated longer postoperative mechanical ventilation time in the on-pump group [1,2]. Only Scott et al. [14] used a fasttrack protocol and reported a significantly shorter ventilation time after off-pump surgery ( $7.4 \mathrm{~h}$ vs. $5.8 \mathrm{~h}$ ). In our study, the extubation time was overall much shorter than that reported by Scott et al. without significant differences between the groups (on-pump 75 min vs. off-pump $80 \mathrm{~min}$ ). The shorter ventilation time in our study is probably attributable to our fast-track protocol. Additionally, our patients were managed in a specialized PACU with limited opening hours, while in the study by Scott et al., the patients were recovered in an ICU. Probst et al. [16] suggested that the fast-track protocol in specialized PACU leads to shorter mechanical ventilation time when compared to patients managed with the same protocol in ICU, while Graß et al. [17] reported that limited opening hours 
also resulted in a significantly reduced mechanical ventilation time. Furthermore, Scott et al. included unselected patients undergoing primary CABG. In contrast, we preselected patients according to our fast-track protocol (temperature $>36^{\circ} \mathrm{C}$, hemodynamically stable, minimal inotropic support, no signs of bleeding at the end of the operation, agreement of anesthesiologist and surgeon for fast-track protocol) [9].

In our study, the fast-track failure was comparable between the two groups. Fast-track failure rates vary in the literature between 11 and $16 \%$ [7] with a peak of $45.5 \%$ reported by Kogan et al. [18] due to a variety of definitions and different patient populations. The most common definitions are: mechanical ventilation time more than six hours and/or stay in the ICU $>24 \mathrm{~h}$, which mostly matches the definition of primary fast-track failure in this study (Figure 1). Our primary fast-track failure rate was $6 \%$ for off-pump and $8.2 \%$ for on-pump patients and therefore lower than in previously published studies $[7,18]$. This might be due to the preselection of patients in our fast-track protocol and due to a different study population. However, there are no studies to date, to the best of our knowledge, comparing fast-track failure rates between on- vs. off-pump CABG.

Interestingly, there was no significant difference between on- and off-pump CABG in terms of PACU, IMC, and in-hospital length of stay. In contrast to our data, previous studies $[2,18,19]$ and systematic reviews $[1,3]$ reported a shorter hospital length of stay after off-pump CABG with conventional perioperative anesthetic management. Similarly, in a fast-track setting, Scott et al. [14] reported a shorter hospital length of stay after off-pump CABG. However, it must be taken into account that different reimbursement strategies, which vary from country to country, may affect hospital length of stay.

In agreement with previously published data, postoperative outcomes and complications were not significantly different in our study population [14,20].

Patients after on-pump CABG had a statistically significant lower in-PACU blood loss compared to patients after off-pump CABG; however, we considered the statistically significant difference of less than $100 \mathrm{~mL}$ as not clinically relevant. Our data only represent the blood loss until discharge from PACU and cannot account for the total postoperative blood loss. This is in line with Potger et al. [21] who did not report significant differences in chest drainage during the first $12 \mathrm{~h}$ after on- vs. off-pump CABG. Contrary to these findings, patients after on-pump CABG received significantly more RBC transfusion compared to those in the off-pump CABG. This is in agreement with systematic reviews [3,22] which reported a reduced postoperative transfusion rate in off-pump CABG surgery. Shaefi et al. [3] suggested that this might be partly due to hemodilution and hemolysis during CPB. Potger et al. [21] founded that intraoperative hemodilution, but not postoperative bleeding or re-operations for bleeding, is an independent risk factor for RBC transfusion, thus explaining our discrepancies between lower blood loss and more RBC transfusion in the on-pump group.

Our study has several limitations: Due to its retrospective design, we cannot fully exclude the risk of unknown biases. Since this was a single-center study with long-term experience in a specialized fast-track protocol, the data may not apply to other centers using standard perioperative anesthetic management. Furthermore, we included, as mentioned, due to our fast-track protocol, only preselected patients operated upon weekdays between 08:00 a.m. and 07:00 p.m. Finally, handwritten anesthesia and PACU observation charts may give room for misinterpretation and lack of data. To overcome some of these limitations, we included a large population size and performed propensity score matching.

\section{Conclusions}

For CABG patients, the surgical approach does not seem to result in significant differences regarding ventilation times, length of stay in PACU, IMC, or hospital, and fast-track failure when the patients are managed with a specialized fast-track protocol. $\mathrm{RBC}$ transfusion was higher in on-pump CABG. 
Author Contributions: Conceptualization, W.Z.A.Z., H.G., A.F.F. and J.E.; methodology, W.Z.A.Z. and H.G.; software, W.Z.A.Z.; validation, W.Z.A.Z., H.G. and A.F.F.; formal analysis, W.Z.A.Z.; investigation, H.G.; resources, W.Z.A.Z.; data curation, W.Z.A.Z., H.G. and A.F.F.; writing-original draft preparation, H.G., W.Z.A.Z. and A.F.F.; writing-review and editing, A.F.F., J.E., M.M. and A.J.; visualization, W.Z.A.Z. and H.G.; supervision, W.Z.A.Z.; project administration, W.Z.A.Z. All authors have read and agreed to the published version of the manuscript.

Funding: This research received no external funding.

Institutional Review Board Statement: This study was conducted according to the guidelines of the Declaration of Helsinki and approved by the local Ethics Committee of "Medizinische Fakultät Universität Leipzig" (178/19-ek from 30 April 2019).

Informed Consent Statement: Individual patient consent was waived given the retrospective observational nature of the study.

Data Availability Statement: The datasets generated and analyzed during the current study are available from the corresponding author on reasonable request.

Conflicts of Interest: The authors declare no conflict of interest.

\section{References}

1. Dieberg, G.; Smart, N.A.; King, N. On- vs. off-pump coronary artery bypass grafting: A systematic review and meta-analysis. Int. J. Cardiol. 2016, 223, 201-211. [CrossRef] [PubMed]

2. Al-Ruzzeh, S.; George, S.; Bustami, M.; Wray, J.; Ilsley, C.; Athanasiou, T.; Amrani, M. Effect of off-pump coronary artery bypass surgery on clinical, angiographic, neurocognitive, and quality of life outcomes: Randomised controlled trial. BMJ 2006, $332,1365$. [CrossRef] [PubMed]

3. Shaefi, S.; Mittel, A.; Loberman, D.; Ramakrishna, H. Off-Pump Versus On-Pump Coronary Artery Bypass Grafting-A Systematic Review and Analysis of Clinical Outcomes. J. Cardiothorac. Vasc. Anesth. 2019, 33, 232-244. [CrossRef] [PubMed]

4. Parissis, H.; Mbarushimana, S.; Ramesh, B.C.; Parissis, M.; Lampridis, S.; Mhandu, P.; Al-Alao, B. The impact of off-pump surgery in end-organ function: Practical end-points. J. Cardiothorac. Surg. 2015, 10, 159. [CrossRef]

5. Cheng, D.C.; Karski, J.; Peniston, C.; Raveendran, G.; Asokumar, B.; Carroll, J.; David, T.; Sandler, A. Early tracheal extubation after coronary artery bypass graft surgery reduces costs and improves resource use. A prospective, randomized, controlled trial. Anesthesiology 1996, 85, 1300-1310. [CrossRef]

6. Zakhary, W.Z.A.; Turton, E.W.; Ender, J.K. Post-operative patient care and hospital implications of fast track. Eur. Heart J. Suppl. 2017, 19, A18-A22. [CrossRef]

7. Wong, W.T.; Lai, V.K.; Chee, Y.E.; Lee, A. Fast-track cardiac care for adult cardiac surgical patients. Cochrane Database Syst. Rev. 2016, 9, CD003587. [CrossRef]

8. Ender, J.; Borger, M.A.; Scholz, M.; Funkat, A.K.; Anwar, N.; Sommer, M.; Mohr, F.W.; Fassl, J. Cardiac surgery fast-track treatment in a postanesthetic care unit: Six-month results of the Leipzig fast-track concept. Anesthesiology 2008, 109, 61-66. [CrossRef]

9. Zakhary, W.; Lindner, J.; Sgouropoulou, S.; Eibel, S.; Probst, S.; Scholz, M.; Ender, J. Erratum to 'Independent Risk Factors for Fast-Track Failure Using a Predefined Fast-Track Protocol in Preselected Cardiac Surgery Patients'. J. Cardiothorac. Vasc. Anesth. 2017, 31, 1150. [CrossRef]

10. Reis, J.; Mota, J.C.; Ponce, P.; Costa-Pereira, A.; Guerreiro, M. Early extubation does not increase complication rates after coronary artery bypass graft surgery with cardiopulmonary bypass. Eur. J. Cardiothorac. Surg. 2002, 21, 1026-1030. [CrossRef]

11. Celkan, M.A.; Ustunsoy, H.; Daglar, B.; Kazaz, H.; Kocoglu, H. Readmission and mortality in patients undergoing off-pump coronary artery bypass surgery with fast-track recovery protocol. Heart Vessels 2005, 20, 251-255. [CrossRef]

12. van Mastrigt, G.A.; Maessen, J.G.; Heijmans, J.; Severens, J.L.; Prins, M.H. Does fast-track treatment lead to a decrease of intensive care unit and hospital length of stay in coronary artery bypass patients? A meta-regression of randomized clinical trials. Crit. Care Med. 2006, 34, 1624-1634. [CrossRef] [PubMed]

13. Cheng, D.C.; Wall, C.; Djaiani, G.; Peragallo, R.A.; Carroll, J.; Li, C.; Naylor, D. Randomized assessment of resource use in fast-track cardiac surgery 1-year after hospital discharge. Anesthesiology 2003, 98, 651-657. [CrossRef]

14. Scott, B.H.; Seifert, F.C.; Grimson, R.; Glass, P.S. Resource utilization in on- and off-pump coronary artery surgery: Factors influencing postoperative length of stay-an experience of 1746 consecutive patients undergoing fast-track cardiac anesthesia. $J$. Cardiothorac. Vasc. Anesth. 2005, 19, 26-31. [CrossRef] [PubMed]

15. Zakhary, W.Z.A.; Turton, E.W.; Flo Forner, A.; von Aspern, K.; Borger, M.A.; Ender, J.K. A comparison of sufentanil vs. remifentanil in fast-track cardiac surgery patients. Anaesthesia 2019, 74, 602-608. [CrossRef]

16. Probst, S.; Cech, C.; Haentschel, D.; Scholz, M.; Ender, J. A specialized post anaesthetic care unit improves fast-track management in cardiac surgery: A prospective randomized trial. Crit Care 2014, 18, 468. [CrossRef] [PubMed]

17. Grass, C.; Stretti, F.; Zakhary, W.; Turton, E.; Sgouoropoulou, S.; Mende, M.; Ender, J. Impact of the post-anesthetic care unit opening hours on fast-track success in cardiac surgery. Minerva Anestesiol. 2017, 83, 155-164. [CrossRef] 
18. Kogan, A.; Ghosh, P.; Preisman, S.; Tager, S.; Sternik, L.; Lavee, J.; Kasiff, I.; Raanani, E. Risk factors for failed "fast-tracking" after cardiac surgery in patients older than 70 years. J. Cardiothorac. Vasc. Anesth. 2008, 22, 530-535. [CrossRef]

19. Puskas, J.D.; Williams, W.H.; Duke, P.G.; Staples, J.R.; Glas, K.E.; Marshall, J.J.; Leimbach, M.; Huber, P.; Garas, S.; Sammons, B.H.; et al. Off-pump coronary artery bypass grafting provides complete revascularization with reduced myocardial injury, transfusion requirements, and length of stay: A prospective randomized comparison of two hundred unselected patients undergoing off-pump versus conventional coronary artery bypass grafting. J. Thorac. Cardiovasc. Surg. 2003, 125, 797-808. [CrossRef] [PubMed]

20. Moller, C.H.; Penninga, L.; Wetterslev, J.; Steinbruchel, D.A.; Gluud, C. Off-pump versus on-pump coronary artery bypass grafting for ischaemic heart disease. Cochrane Database Syst. Rev. 2012, CD007224. [CrossRef] [PubMed]

21. Potger, K.C.; McMillan, D.; Southwell, J.; Connolly, T.; Smith, K.K.; Ambrose, M. Transfusion and bleeding in coronary artery bypass grafting: An on-pump versus off-pump comparison. J. Extra Corpor. Technol. 2007, 39, 24-30. [PubMed]

22. Guan, Z.; Guan, X.; Gu, K.; Lin, X.; Lin, J.; Zhou, W.; Xu, M.; Wan, F.; Zhang, Z.; Song, C. Short-term outcomes of on- vs off-pump coronary artery bypass grafting in patients with left ventricular dysfunction: A systematic review and meta-analysis. J. Cardiothorac. Surg. 2020, 15, 84. [CrossRef] [PubMed] 